\title{
Optimizing university acceleration programs. The case of NKUA's multistage model
}

\author{
Antonios D. Livieratos ${ }^{\uparrow}$, Vasilis Siemos ${ }^{2}$ \\ ${ }^{1}$ Department of Business Administratiom, National and Kapodistrian University of Athens, Greece \\ 2 Arcimedes Center for Research, Innovation and Entrepreneurship, National and Kapodistrian University of Athens, Greece
}

\begin{tabular}{l}
\hline ARTICLE INFO \\
\hline Article History \\
Received 2 August 2021 \\
Accepted 4, October 2021 \\
\hline JEL Classifications \\
M13, L26, L30, O31
\end{tabular}

ABSTRACT

\section{Purpose:}

Business accelerators have rapidly emerged as prominent players in the entrepreneurial ecosystem. A key strategic decision in designing acceleration programs is whether to customize or standardize the new venture development program (Cohen et al., 2019). Recognizing a trade-off between customization and standardization, the paper presents a multistage acceleration model aiming to harvest benefits of standardization while keeping several advantages found in tailor-made acceleration programs.

Design/methodology/approach:

The here-proposed 3-stage acceleration model was developed to serve the needs of the recently established business accelerator of the National and Kapodistrian University of Athens (NKUA). As the authors have developed and are currently implementing the 'Archimedes Multistage Acceleration Model' they act as change agents aiming to solve practical problems. This enabled the adoption of an action research approach where the aim is to produce knowledge to change social reality rather than vice versa (Allard-Poesi and Perret, 2003). To that end, the Action Innovation Management Research framework (Guertler et al., 2020) constitutes the basis of this research.

\section{Findings:}

The 'Archimedes Multistage Acceleration Model' proposes a 3-stage acceleration program where each stage matches a different level of maturity. For those statups positioned in the first two stages the aim is to progressively (and selectively) assist them through to the next stages. This model may be regarded as a funnel where startups are initially supported in the framework of a highly standardized acceleration program, ending gradually to receive highly tailored-made services. This design serves the needs of university accelerators that

Keywords:

Accelerator, Startup.

National and Kapodistrian

University of Athens, Case

study, Lean startup,

University, Innovation,

Action Research target a subset of the local startup ecosystem and aim to foster an entrepreneurship culture.

Research limitations/implications:

'Archimedes Multistage Acceleration Model' was developed for, and up to this point applied at NKUA for almost a year. It is widely accepted that effectively supporting startups is a long-term process and as such a model serving this purpose requires more time to demonstrate its full potential. Furthermore, the application of the model at other universities will provide further evidence on both its value for other business accelerators and its transferability.

Originality/value:

Despite the growing interest in business accelerators, university accelerators remain an overlooked topic in the literature. The paper proposes a new acceleration model and presents how this is applied in the case of the Archimedes Center of NKUA. The model that harvests benefits of standardization while keeping several advantages found in tailor-made acceleration programs, is especially designed to serve the needs and the objectives of university accelerators.

${ }^{\dagger}$ Corresponding Author:Antonios D. Livieratos

Email: alivoeratos@ba.uoa.gr 


\section{Introduction}

Since the first accelerator program offered by Y Combinator in 2005, accelerators have become popular during the last decade (Cohen et al. 2019a; Hathaway, 2016). They have rapidly emerged as prominent players in the entrepreneurial ecosystem (Hallen, et al., 2019) gradually replacing the up until recently dominant concept of incubator (Pauwells et al., 2016) both in developed as well as emerging markets (Roberts and Kempner, 2017). As a number of studies find a positive impact of acceleration on startups (Winston et al., 2013; Hallen et al., 2019; Dams et al., 2016), accelerators may also regarded as public intervention tools (Sheng et al., 2020) increasing, thus, the 'demand' for designing new accelerator programs (Cohen et al., 2019b). Despite having common elements such as education, coaching, mentorship, networking and financing (Hathaway, 2016), there is significant variation in accelerators along multiple design features (Cohen et al., 2019a).

A key strategic decision in designing accelerator programs is whether to customize or standardize the new venture development program. Cohen et al. (2019b) call this decision 'the extent of customization'. Accordingly, some accelerators encourage ventures to follow individualized programs around their unique knowledge and needs while others standardize the set of activities and sequence the venture development process (Cohen et al., 2019b). We identify this as an important trade-off with serious implications.

Standardization has two interrelated problems. Firstly, startups of different maturity levels essentially end up following a one-size-fits-all program. This could be avoided by choosing startups of a similar maturity level. However, where the 'supply' of quality startups is limited this may hinder the creation of high-quality cohorts. This is especially the case in less developed startup ecosystems (Startup Genome, 2021). Secondly, where tailored programs exist it is ultimately up to the founders to determine which events to attend. But this too has downsides with fewer common activities and, thus, loss of 'peer effect' in mutual learning benefits, as well as in networking (Smith et al., 2016; Miller and Bound, 2011).

Recognizing the trade-off between standardization and customization, the paper aims to present a new multistage accelerator model and how this is applied in practical terms. The here-proposed 'Archimedes Multistage Acceleration Model' aims to harvest benefits of standardization, while keeping several advantages found in tailor-made acceleration programs. This model is highly relevant in less-developed entrepreneurial ecosystems where the supply of startups is limited.

The here-proposed 'Archimedes Multistage Acceleration Model' was developed to address the needs and challenges of the newly established Archimedes accelerator of the National and Kapodistrian University of Athens that is operating in a startup ecosystem under development. As the authors have developed and are currently implementing the 'Archimedes Multistage Acceleration Model' they act as change agents aiming to solve practical problems. To that end, the Action Innovation Management Research framework (Guertler et al., 2020) constitutes the basis of this research.

The rest of the paper is organized as follows. In the next section we review acceleration programs and acceleration programs design. The following part presents the research methodology and in turn the 'Multistage Acceleration Model' along with how it is applied in in the case of the Archimedes accelerator. Finally, findings of the research are discussed. We conclude our study with a brief discussion of the limitations of our study and present directions for future research.

\section{Acceleration Programs and Acceleration Programs Design}

Entrepreneurship support structures appeared initially at the end of the 1950 s in the form of business incubators in the US (Kilcrease, 2012). However, the concept did not receive great attention till the 1980 s when gradually a great number of incubators emerged mainly in the US and in Europe (Bruneel et al., 2012). This $1^{\text {st }}$ generation of incubators offered affordable office space and shared resources (Barrow, 2001). As governments in the US and Europe were confronting increased unemployment rates (Reich, 1991) and in parallel new technology-based firms were considered as job creators and economic growth generators (Tether \& Storey, 1998), incubators have adapted by enriching their services. They started offering proactive business support, networking, and coaching (Bruneel et al., 2012). However the demand for startup support has further shifted as in the early 2000 s the internet had already shortened the product life cycle (Cao \& Folan, 2012) and the burst of the 'dot com' bubble decreased considerably funding opportunities for startups (Goldfarb et al., 2007). Responding to this new era, a new concept under the name 'Business Accelerator' was introduced by Y Combinator in 2005 (Hallen et al., 2019). This new concept has shortened the support cycle and provided seed funding to early stage startups. In parallel, the rise of the lean startup approach (see Blank, 2013; Ries 2011; Mayrya, 2012), boosted further the widespread of the concept. The result was a radical shift from incubation to acceleration as the prevailing startup support structure of the 2010s (Pauwels et al., 2016). The main differences between the previous mainstream model of startup support (incubation) and the new one (acceleration) concern the duration of the supporting period, the organizing in cohorts, the business model and the mentorship (see table 1).

Table 1 Difference between incubators and accelerators

\begin{tabular}{|l|l|l|}
\hline & Incubator & Accelerator \\
\hline Duration & 1 to 5 years & 3 to 12 months \\
\hline Cohorts & No & Yes \\
\hline Business model & Rent; Non-profit & $\begin{array}{l}\text { Investment, can } \\
\text { also be non-profit }\end{array}$ \\
\hline
\end{tabular}




\begin{tabular}{|l|l|l|}
\hline Selection & Non-competitive & Competitive \\
\hline Stage & Early or late & Early \\
\hline Education & $\begin{array}{l}\text { Ad hoc, human } \\
\text { resources, legal }\end{array}$ & $\begin{array}{l}\text { Seminars (mostly } \\
\text { mandatory) }\end{array}$ \\
\hline Mentorship & Minimal, tactical & $\begin{array}{l}\text { Intense, by self } \\
\text { and externals }\end{array}$ \\
\hline \multicolumn{2}{|c|}{ Source: Adapted by Hathaway (2016) }
\end{tabular}

While several initiatives call themselves acceleration programs, not all necessarily meet a set of minimum criteria that would distinguish them from other initiatives, such as incubators, venture studios, startup competitions or angel investors (Cohen et al., 2019a). Accelerators are limited-duration programs that help cohorts of founders to build and launch their ventures (Cohen et al., 2019a). They support early stage startups through education, coaching, mentorship, networking and financing (Hathaway, 2016). Accelerators directly provide capital or alternatively support startups via fund raising (Busulwa et al., 2020) and function as fixed term, cohort-based, and mentorshipdriven program with a concluding graduation event (Cohen et al., 2019a). This event takes in most of the times the form of a startup demo-day giving participants the chance to pitch their venture to a large audience including investors (Hathaway, 2016; Cohen, 2013).

Two definition elements distinguish accelerators from other initiatives: the fixed-term and the cohort nature of the programs (Cohen et al., 2019a). During the acceleration period, startups can leverage resources such as education, coaching, mentoring and office space. The fixed-term nature of these ensures that startups are forced to contend with market forces, rather than being sheltered (or incubated) from them (Cohen et al., 2019a). The cohort nature of the acceleration programs aims, on the one hand, to enable basic agglomeration and support across startups (Cohen et al., 2018) and, on the other hand, to enable 'peer effects' in learning and networking (Smith et al., 2016; Miller and Bound, 2011).

Accelerators may be non-profit or for-profit by providing equity and expecting return their investment. Accelerators may vary in the amount of the equity stake taken, in the length of the program, in the availability of coworking space and in industry vertical focus. Accelerators may be affiliated with investor groups or business angels, venture capitals, corporations (corporate accelerators), universities (university accelerators), local governments (e.g. municipality accelerators) or non-governmental organizations (Cohen and Hochberg, 2014). In cases where accelerators are affiliated with a larger organization it is the later that formulates their strategy and, in turn, the design of their program by complementing or even advancing the strategy of the parent organization (Brigl et al., 2017). One such case are also university accelerators. Accelerators operating within a university context aim either to create a valuable experience (Adomdza, 2016), to foster innovation (Wise \& Valliere, 2014) or to support technology transfer (Crisan et al., 2021). Despite sporadic effort (see Breznitz \& Zhang, 2019; Drori \& Wright, 2018; Metcalf et al., 2020; Thomson, 2019; Wright et al., 2017) to explore the phenomenon, little research has been conducted on the operation of university accelerators and how they design their acceleration process as part of the organization's broader strategy (Breznitz \&Zhang, 2019).Cohen et al. (2019a) recognize three main design choices in the development of an acceleration program: a) consultation intensity, b) disclosure level and c) extent of customization. The extent of customization, which is the main focus of this research, is about the degree accelerators allow ventures to decide what activities to attend based on their perceived needs. Cohen et al. (2019a) assesses the extend of customization by examining whether accelerator designs require ventures to (1) choose their own mentors or meet with assigned mentors, (2) interact with their cohorts on an ad-hoc basis or attend regularly scheduled peer gatherings, (3) choose which workshops to attend or attend a prescribed set of workshops, and (4) follow a standardized sequence of activities. These four elements related to the extent of customization will be later used to assess the degree of customization of each of the stages of the here-proposed 'Archimedes Multistage Acceleration Model'.

\section{Methodology}

\subsection{An action Research Approach}

Action research is a problem-oriented approach to conduct research (Guertler et al., 2020) which provides rigor and relevance (Levin, 2012) and, as such, it responds to recent calls for more problem-based research (Benner and Tushman, 2015). The term 'action research' entails a family of methodologies that pursue action and research simultaneously (Dick, 1997). Just like in the present research, these methodologies implicate researchers who are actors of change that actively participate in the resolution of a specific matter of genuine concern producing results for both academic and practitioner communities (Swann, 2002; Livieratos, 2009).

In the study reported in this paper, all authors are directly implicated in the establishment and management of the business accelerator of the National and Kapodistrian University of Athens and are thus acting as change agents. Aiming to respond to a number of challenges related to the establishment and operation of an accelerator in a large multidisciplinary university, the authors developed the here-proposed 'Archimedes Multistage Acceleration Model'. This enabled the adoption of an action research approach where the aim is to produce knowledge to change social reality rather than vice versa (Allard-Poesi and Perret, 2003). The aim of this paper is to develop and present a model for business acceleration. It is therefore within the scope of this study to deduct knowledge and best practice from addressing a problem. As such, action research is an appropriate approach to use for addressing the research question. 
Being part of the broader field of innovation management, business acceleration entails high level of novelty and uncertainty that requires pivots (Hidalgo and Albors, 2008), the problems and the context present a sociotechnical nature of (D'Alvano and Hidalgo, 2012) and it implicates a broad range of stakeholders and relationships (Carayannis et al., 2012). Recognizing the importance of these characteristics for the present research, the Action Innovation Management Research (AIM-R) framework is adopted (Guertler et al., 2020). Based on this framework research is conducted in five phases: 1) Analysis and framing, 2) Project planning, 3) Executing on action, 4) Reflecting and learning, 5) Communicating and pivoting.

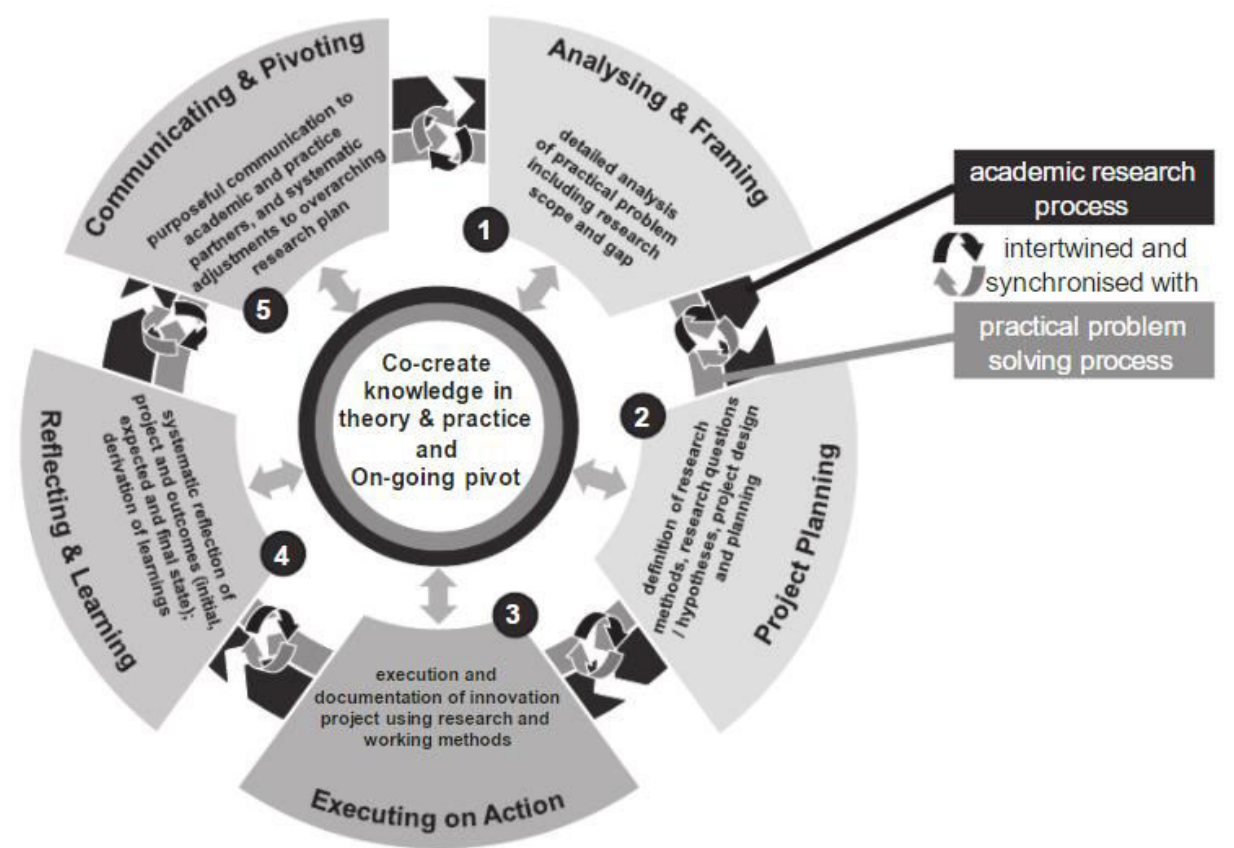

Figure 1: The Action Innovation Management Research framework, Source: Guertler et al., 2020

\subsection{The Action Research Process Implemented in this Study}

Research setting. NKUA was founded in 1837 and is the oldest university of the Eastern Mediterranean region. Today NKUA has more than 2,200 professors and researchers, 45,000 undergraduates and 24,000 postgraduate students. It offers 41 undergraduate programs and 205 postgraduate programs in a broad range of fields such as biology, medicine, informatics, business administration and literature. In September 2019 NKUA started the operation of the Archimedes Center of Research, Innovation and Entrepreneurship. The Archimedes center offers business acceleration and TT services to all departments and laboratories. As these two activities were considered complementary, they are hosted under the same organization. Following the five-phase AIM-R model proposed by Guertler et al. (2020) the action research was organized and executed as follows.

Phase 1 - Analysis and Framing. Prior to the establishment of a business accelerator, startup support was conducted in the framework of an 'executive training' course addressed to startup founders. The "Entrepreneurship in Action" program operating from 2014 till 2018 was a yearly program offering 100 hours of teaching. In parallel, it was offering coaching for developing a business plan and its final event was an open demo day in the form of a startup contest. Operating this program was a valuable experience for the design and development of a university acceleration program. On that basis, the senior management of the University commissioned the head of the "Entrepreneurship in Action" program to set up the Archimedes Center. Interestingly, the provision of technology transfer services was considered as complementary to the support of startups (Livieratos \& Dimitrakopoulos, 2020) and to that end both activities were included into the Archimedes Center that started its operation in 2019.

Phase 2 - Project planning. The authors undertook the mandate to develop a business accelerator at NKUA. At that point, both authors were already experienced in supporting startups and one of them was actively implicated as instructor and coach at the "Entrepreneurship in Action" program. Project planning included the diagnosis of the current situation. The internal and external environment was analysed as well as national and international best practices. In relation to the internal environment several meetings were organized at all levels (undergraduate and postgraduate students, alumni, professors and administration staff) aiming to recognize 'entrepreneurial intent' in the framework of the university's ecosystem. In relation to the external environment a great number of meetings were organized at national and international level aiming to build a network of stakeholders and/or exchange experiences. A structured literature analysis was initiated from an early stage of this phase. Interestingly, it came out that cooperation among business and the university was a main concern of the Greek entrepreneurship community. A recent study indicated that a great number of firms asked for support in this domain (Katimertzopoulos \& Vlados, 2017). Given the limited resources, priorities were set, and in turn, it was decided how acceleration would be offered. 
Phase 3 - Executing on action. The diagnostic phase revealed mainly two reasons prohibiting the copy of one of the existing acceleration models in the case of NKUA. The first is that a university accelerator aims besides building startups also to foster an entrepreneurship culture within the university and the second was related to the fact that the Greek startup ecosystem is under development and severely affected by the Greek crisis (GEM, 2019). Adopting a lean startup viewpoint (Blank, 2013; Ries 2011; Mayrya, 2012) on how to initiate actions during the first year of its operation, the accelerator experimented with several models. Initially it started offering mostly tailored-made services, supporting in total 28 startups. On that basis a new multistage acceleration program was designed in midsummer 2020 and became operational since September 2020.

Given the fact that the accelerator's aim besides supporting NKUA founders is also to foster an entrepreneurship culture in the university's community, awareness raising activities were very important at this stage. The Archimedes team started contacting all professors and especially those that are somehow implicated in business and economics courses (including a handful of entrepreneurship courses). Students from these courses coming from faculties other than business and economics were more interested in starting a company and in turn seek for acceleration services. In parallel, activities beyond the university started taking place. The Archimedes accelerator started taking an active role in the startup ecosystem's events and appeared regularly in the relevant media. As NKUA is quite a big university, it has proven that more than half of the startups have a member that is somehow related to the university. As a result, awareness raising activities generally towards the Athens startup ecosystem were also proven effective.

Phase 4-Reflecting and learning. The 'Archimedes Multistage Acceleration Model' is operating for more than one year. During this period, the internal and external network that was developed during the previous phases contributed by providing feedback and ameliorating the model. In parallel, the users of the model, namely startup founders have also contributed by providing feedback. In parallel, the model was presented at the ISPIM Conference (December 2020, Livieratos \& Siemos, 2020) during which academia and practitioners from the field of innovation management and entrepreneurship provided feedback. Moreover, the here-proposed model was presented in various occasions at national and international level (CIVIS Alliance, GAZELLE EU project) so as to exchange experiences with other similar structures and get feedback.

Phase 5-Communicating and pivoting. The aim of the present paper is to communicate the 'Archimedes Multistage Acceleration Model' to a wider audience. Moreover, the model will be part of an online toolbox for startup support schemes developed in the framework of the Gazelle project. More feedback is expected by these communication actions that will enable further amelioration of the model and its practical application.

\section{The Archimedes Multistage Acceleration Model}

The 'Archimedes Multistage Acceleration Model' is developed to address the needs and challenges of the newly established accelerator of the National and Kapodistrian University of Athens (NKUA). The prerequisite for supporting an entrepreneurial team is that at least one of the founders must have some connection to NKUA (student, researcher, faculty member, employee or alumni). Given the nature of the university and the development of the ecosystem, the mandate was to support ventures from all industries with a wide variety in terms of maturity. Moreover, recognizing that the stereotypical role of women in seeking sole careers is preventing future growth in female entrepreneurship (Dimitriadis et al., 2018), special consideration was also given to this type of entrepreneurship as well as to youth entrepreneurship (Karadzic et al., 2015). To that end, the Archimedes accelerator is supporting startups from an early stage prior to incorporation, up to startups that operate up to three years. The following case material offers three key insights into the startup variety:

- Pave Studios is a startup established by a team of three "Escape Room" entrepreneurs and a developer/'escape room enthusiast'. When they entered the Archimedes accelerator, they had nothing else than a vision: "to digitalize the Escape Room experience and transfer it outdoors". Approximately ten months later Pave Studios launched their first mobile game entitled "The Timeless".

- Adwork offers artificial intelligence processing for semantic description and object recognition from all kinds of video and embedded marketing techniques to AI-assisted scene recognition supporting Virtual Product Placement. Adworks' founders have long experience in the TV market. When Adwork entered the Archimedes accelerator they had 'verified the problem' and were about to finalize their Alpha version.

- Give Engineering is a startup created by a team of F 1 engineers aiming to develop electric scooters. When Give Engineering entered the Archimedes accelerator, they had finalized a working prototype, submitted several patents, raised seed funding, obtained client letters of intent and had prepared a well-written business plan. Their aim was to raise round A to support production and sales.

In support of this diverse audience of startups and in response to the trade-off described earlier, a 3-stage acceleration program was designed. Each stage matches a different level of maturity and has a duration of 4 months. At the end of the 1st stage the output is a validated business model, at the end of the 2 nd stage the output is a business plan and at the end of the 3rd stage the aim is funding and/or sales. Startup selection going forward incorporates a maturity assessment to position applicants into one of the three stages. In reference to the above cases, Pave Studios would be positioned into the 1st stage, Adwork into the 2nd stage and Give Engineering into the 3rd stage (see Figure 2).

For those startups positioned in the first two stages the aim is to progressively (and selectively) assist them through to the next stages. Startups entering at any stage are offered mentoring by a pool of mentors, coaching by the accelerator managers, education in the form of workshops and a co-working space to work and meet in their day-today activities in the city center of Athens. It is still possible for startups to follow activities from other stages if there are specific gaps identified. 


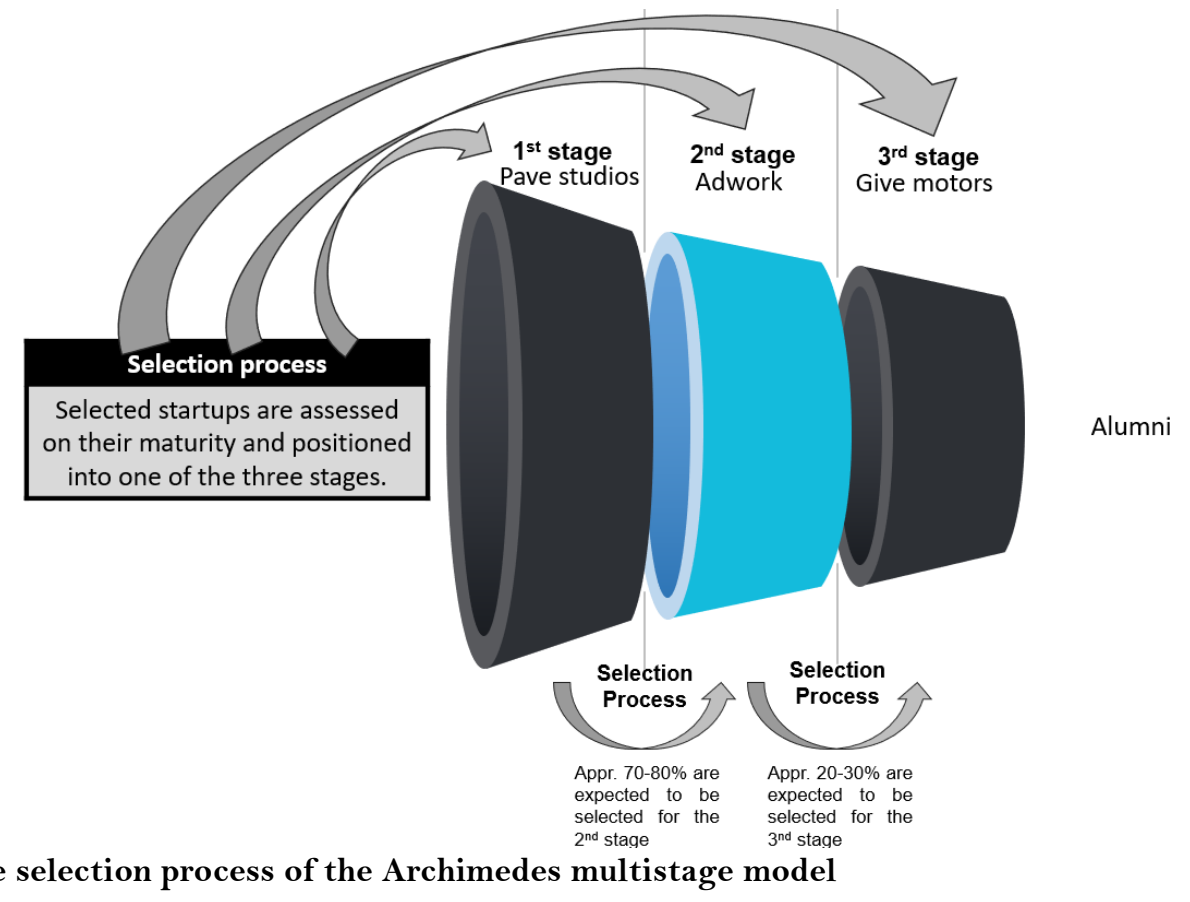

The modus operandi of the acceleration program for each stage is the following:

$\mathbf{1}^{\text {st }}$ stage. During the $1^{\text {st }}$ stage startups have to attend ten workshops and have to give-in a deliverable almost every week. At the end of the $2^{\text {nd }}$ month startups get a mentor under the condition that they have handed-in their deliverables. At the end of the $1^{\text {st }}$ stage startups present their venture at an internal demo-day in order to get feedback by the Archimedes team, one or two mentors and the peers of the cohort. Overall, during this stage special consideration is given to enhance creativity of startups that is believed to have a positive impact on innovation activity (Botrić, 2015). $2^{\text {nd }}$ stage. Approximately $70-80 \%$ of the startups coming from the $1^{\text {st }}$ stage will make it to the $2^{\text {nd }}$ stage. The cohort is enriched by those startups that have been selected to directly enter the $2^{\text {nd }}$ stage. During the $2^{\text {st }}$ stage startups have to attend four workshops and have to give-in one single deliverable at the end of the fourth month. In parallel, they are advancing their ventures based on coaching by the acceleration managers and the advice of their mentor(s). Smaller milestones are agreed on a regular basis. The $2^{\text {nd }}$ stage ends with an open demo day attended by investors, venture capitals, corporates and academics.

$3^{\text {rd }}$ stage. Approximately $20-30 \%$ of the startups coming from the $2^{\text {nd }}$ stage will make it to the $3^{\text {rd }}$ stage. The cohort is enriched by those startups that have been selected to directly enter the $3^{\text {rd }}$ stage. Activities at this stage are fully customized based on coaching by the acceleration managers and the advice of their mentor(s). The main aim for startups entering this stage is sales and/or funding. Figure 3 presents the structure and the timeframe of the multistage acceleration model as well as the objectives, the workshops and the deliverables for each stage. 


\begin{tabular}{|c|c|c|c|c|c|c|}
\hline & & $1^{s t}$ & le & & $2^{\text {nd }}$ stage & $3^{\text {rd }}$ stage \\
\hline$\stackrel{\text { हू }}{=}$ & $1^{\text {st }}$ month & $2^{\text {nd }}$ month & $3^{\text {rd }}$ month & $4^{\text {th }}$ month & $5^{\text {th }}-8^{\text {th }}$ month & $9^{\text {th }}-12^{\text {th }}$ month \\
\hline 竎 & $\begin{array}{l}\text { Find an idea or problem } \\
\text { worth pursuing }\end{array}$ & Find problen & /solution fit & Find product/market fit & $\begin{array}{l}\text { I Strategy / Operational / } \\
\text { I Financial validation }\end{array}$ & $\begin{array}{l}\text { I } \\
\text { I Operational execution } \\
\text { I }\end{array}$ \\
\hline 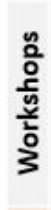 & $\begin{array}{l}\text { - Customer Discovery I } \\
\text { - Business Model Canvas }\end{array}$ & $\begin{array}{l}\text { - Marketing } \\
\text { Total Addressable } \\
\text { Market (TAM) } \\
\text { - Customer Discovery II }\end{array}$ & $\begin{array}{l}\text { I. Branding } \\
\text { I. Digital Marketing } \\
\text { I. Startup team building } \\
\text { I }\end{array}$ & - Pitching & $\begin{array}{l}\text { I- Legal/Accounting } \\
\text { I: Intellectual Property } \\
\text { I. HR-Recruiting } \\
\text { I. Business Plan } \\
\text { (including financials) }\end{array}$ & $\begin{array}{l}\text { I- Sales } \\
\text { I: Internationalization } \\
\text { I. Innovation } \\
\text { I management }\end{array}$ \\
\hline$\frac{\square}{\frac{0}{0}}$ & $\begin{array}{l}\text { Three Similar Offerings } \\
\text { Problem Definition } \\
\text { Competitive Analysis } \\
\text { (Benchmarking) }\end{array}$ & $\begin{array}{l}\square \text { Business Model Canvas } \\
\square \text { Total Addressable } \\
\text { Market (TAM) } \\
\square \text { Customers Profile }\end{array}$ & $\begin{array}{l}\text { I } \square \text { Problem verification } \\
\text { I } 9 \text { Team manifesto } \\
\text { I Corporate Identity } \\
\text { I Landing page/Social } \\
\text { I media }\end{array}$ & $\begin{array}{l}\square \text { MVP } \\
\square \text { "Real life experiments" } \\
\square \text { Elevator Pitch }\end{array}$ & $\begin{array}{l}\text { I } \square \text { Business Plan } \\
\text { | } \\
\text { | } \\
\text { | }\end{array}$ & $\begin{array}{l}\text { I } \square \text { KPIs (sales and funding) } \\
\text { I } \\
\text { I } \\
\text { I }\end{array}$ \\
\hline & & $\begin{array}{l}8 \% 8 \\
\vdots 98 \\
8\end{array}$ & $\begin{array}{l}\text { Mentor } \\
\text { Matching }\end{array}$ & & $\begin{array}{l}\text { I Internal } \\
\text { Demo } \\
\text { Day }\end{array}$ & $\begin{array}{l}\text { Open } \\
\text { Demo } \\
\text { Day }\end{array}$ \\
\hline
\end{tabular}

Figure 3: NKUA's Archimedes multistage acceleration program 
Under this model, there are three call-outs per year for potential startup participants. Having three call-outs per year results that the Archimedes accelerator works simultaneously with all stages all around the year. Following Cohen et al. (2019b) we assess the extent of customization of the multistage acceleration model by examining for each one of the stages whether startups:

(1) choose which workshops to attend or attend a prescribed set of workshops,

(2) choose their own mentors or meet with assigned mentors,

(3) interact with the startups of their cohorts on an ad-hoc basis or attend regularly scheduled peer gatherings, and

(4) follow a standardized sequence of activities.

Table 2 presents the design choices of the multistage acceleration model in relation to these four design elements.

Table 2 The extend of customization per stage

\begin{tabular}{|c|c|c|c|}
\hline & $1^{\text {st }}$ stage (4 months) & $2^{\text {nd }}$ stage ( 4 months) & $3^{\text {rd }}$ stage ( 4 months) \\
\hline $\begin{array}{c}(1) \\
\text { Workshops }\end{array}$ & $\begin{array}{l}\text { Teams have to attend } 20 \text { hours } \\
\text { of workshops. Teams may also } \\
\text { attend workshops of the other } \\
\text { stages if necessary. } \\
\text { Workshops take place on } \\
\text { Tuesdays. }\end{array}$ & $\begin{array}{l}\text { Teams have to attend } 12 \\
\text { hours of workshops. Teams } \\
\text { may also attend workshops of } \\
\text { the other stages if necessary. } \\
\text { Workshops take place on } \\
\text { Wednesdays. }\end{array}$ & $\begin{array}{l}\text { Teams may attend } 9 \text { hours } \\
\text { of workshops. Workshops } \\
\text { are not mandatory at this } \\
\text { stage. } \\
\text { Teams may also attend } \\
\text { workshops of the other } \\
\text { stages if necessary. } \\
\text { Workshops take place on } \\
\text { Thursdays. }\end{array}$ \\
\hline $\begin{array}{c}(2) \\
\text { Mentors }\end{array}$ & $\begin{array}{l}\text { Mentors are assigned at the } \\
\text { end of the } 2^{\text {nd }} \text { month to the } \\
\text { teams that have successfully } \\
\text { completed their deliverables up } \\
\text { to that point. } \\
\text { Acceleration managers discuss } \\
\text { the needs with startups and } \\
\text { propose mentor-startup pairs. } \\
\text { Both parties have to agree on } \\
\text { the matching. As the network } \\
\text { of the university is extensive, } \\
\text { in some cases acceleration } \\
\text { managers are looking for help } \\
\text { beyond the existing pool of } \\
\text { mentors. }\end{array}$ & $\begin{array}{l}\text { Teams coming from the } 1 \text { st } \\
\text { stage keep their mentor. In } \\
\text { some cases, as the venture } \\
\text { progresses, with additional } \\
\text { mentors different } \\
\text { expertise might be assigned, if } \\
\text { needed. } \\
\text { Mentors are assigned directly } \\
\text { for those entering directly the } \\
\text { 2nd stage and the process is } \\
\text { the same as in the 1st stage. }\end{array}$ & $\begin{array}{l}\text { Teams coming from the } \\
\text { 2nd stage keep their } \\
\text { mentor. Just like in the } 2 \text { nd } \\
\text { stage, in some cases, as the } \\
\text { venture progresses, } \\
\text { additional mentors with } \\
\text { different expertise might be } \\
\text { assigned, if needed. } \\
\text { Mentors are assigned } \\
\text { directly for those entering } \\
\text { directly the 3rd stage and } \\
\text { the process is the same as in } \\
\text { the } 1 \text { st stage. }\end{array}$ \\
\hline $\begin{array}{l}\quad(3) \\
\text { Interaction } \\
\text { with cohort }\end{array}$ & $\begin{array}{l}\text { Teams interact with other } \\
\text { members of the cohort during } \\
\text { workshops, during other } \\
\text { events and at the co-working } \\
\text { space. } \\
\text { Accelerator managers initiate } \\
\text { interaction in case of } \\
\text { complementary knowledge. }\end{array}$ & Same as in the 1st stage. & $\begin{array}{l}\text { Same as in the 1st stage. } \\
\text { Unlike the 1st stage } \\
\text { attending workshops is not } \\
\text { mandatory. }\end{array}$ \\
\hline $\begin{array}{l}\quad(4) \\
\text { Sequence of } \\
\text { activities }\end{array}$ & $\begin{array}{lr}\text { Standardized } & \text { sequencing. } \\
\text { Startups have strict deadlines } \\
\text { to gradually hand-in } 12 \\
\text { deliverables. Activities are } \\
\text { organized around these } \\
\text { deliverables. }\end{array}$ & $\begin{array}{l}\text { Partial standardization, in the } \\
\text { sense that startups have to } \\
\text { hand-in one deliverable at the } \\
\text { end of the 2nd stage (fully } \\
\text { structured and sufficiently } \\
\text { documented business plan). } \\
\text { Besides the activities that are } \\
\text { related to the deliverable, all } \\
\text { other activities are } \\
\text { customized. }\end{array}$ & $\begin{array}{l}\text { Activities are fully } \\
\text { customized according to the } \\
\text { needs of the startup, based } \\
\text { on management consulting } \\
\text { experience from the } \\
\text { acceleration managers. }\end{array}$ \\
\hline
\end{tabular}

\section{Discussion}

The Archimedes accelerator of the National and Kapodistrian University of Athens has a relatively small pool of startups that it can choose from for two reasons. The first is that it operates in an entrepreneurial ecosystem under development that is coming out of almost a decade of economic crisis (GEM, 2020; Karafolas and Woźniak, 2020). The second is related to its nature as a university accelerator. In order to be eligible to apply for the Archimedes accelerator, startups need to have at least one member that is somehow connected to the university (alumni, student, faculty, researcher or employee). Targeting a subset of an entrepreneurial ecosystem under development and aiming 
to formulate high-quality cohorts, it was decided to open-up to startups that have a great variety in terms of maturity and derive from all sectors.

Accepting startups with different levels of maturity makes it difficult to design a highly standardized acceleration program. A customized acceleration program is equally not serving the needs of NKUA's accelerator mainly because of the loss of the 'peer effect'. The 'peer effect' was evaluated as too important to neglect, especially in the framework of a university that seeks, among other things, to enhance the community effect and support the creation of entrepreneurial spirit among its members. As a result, it was decided to design an acceleration program that aims to harvest benefits from both design types.

The Archimedes multistage acceleration may be regarded as a funnel where startups are initially supported in the framework of a highly standardized acceleration program offered in Stage 1, ending gradually to receive highly tailored-made services in Stage 3. Choosing to start with a standardized acceleration program is mainly related to the fact that the vast majority of NKUA's founders have neither prior entrepreneurial, nor a business background. Their ideas are unique, but the process they follow is recognized as being very similar. To this end, having a standardized acceleration program during the 1st Stage aims at helping startups establish their own learning curve, becoming thus able to gradually find their own way. Moreover, it is worth adding that every cohort has a number of drop-outs. Previous experience shows that the standardization of activities leads drops-outs to leave earlier. "Failing fast and cheap" serves both the startups and the accelerator.

\section{Limitations and further research}

'Archimedes Multistage Acceleration Model' was developed for, and up to this point applied at NKUA for almost a year. This poses both limitations and directions for future work. It is widely accepted that effectively supporting startups is a long-term process and as such a model serving this purpose requires more time to demonstrate its full potential. Furthermore, the application of the model at other universities will provide further evidence on both its value for other business accelerators and its transferability. Despite these limitations, we firmly believe that the current experience constitutes a solid base that enables the communication of 'Archimedes Multistage Acceleration Model' in various ways, among others with this publication, supporting thus not only its dissemination but also its enhancement, its application and its transferability.

\section{References}

Adomdza, G. K. (2016). Choosing between a student-run and professionally managed venture accelerator. Entrepreneurship: Theory and Practice, 40(4), 943-956.

Allard-Poesi, F. \& Perret, V. (2003). La Recherche-Action, in Giordano, Y. (ed.) Conduire un Projet de Recherche. Une Perspective Qualitative, Chapter 3, EMS, Paris, 85-132.

Breznitz, S. \& Zhang, Q. (2019) Fostering the growth of student start-ups from university accelerators: an entrepreneurial ecosystem perspective, Industrial and Corporate Change, 28(4):855-873

Barrow, C. (2001). Incubator: A realistic guide to the world's new business accelerator. Wiley, West Sussex, UK.

Benner M.J. \& Tushman, M.L. (2015). Reflections on the 2013 Decade Award - "Exploitation, exploration, and process management the productivity dilemma revisited" ten years later. Academy of Management Review, 40(4), 497-514.

Blank, S. (2013). Why lean start-up changes everything. Harvard Business Review, 95(5), May, 3-9.

Botrić, V. (2015). Fostering Innovation Through Creativity Stimulation Methods in Croatia. International Journal of Business and Economic Sciences Applied Research, 8(1), 7-23.

Brigl, M., Roos, A., Schmief, F. \& Watten, D. (2017) Incubators, Accelerators, Venturing, and More, Boston Consulting Retrieved May 3, 2020, from www.bcg.com/en-gr/publications/2014/mergers-acquisitions-growth-incubators-acceleratorsventuring-more.

Bruneel, J., Ratinho, T., Clarusse, B., \& Groen, A. (2012). The evolution of business incubators: Comparing demand and supply of business incubation services across different incubation generations, Technovation, 32(4), 110-121.

Busulwa, R., Birdthistle, N. \& Dunn, S. (2020). Startup Accelerators: A Field Guide, Wiley, New Jersey

Cao, H. \& Folan, P. (2011). Product Life Cycle Theory and the Maturation of the Internet. Production, Planning and Control, 23(8), 641-662.

Carayannis, E.G., Barth, T.D. \& Campbell D.F.J. (2012). The Quintuple Helix innovation model: global warming as a challenge and driver for innovation. Journal of innovation and entrepreneurship, 1(1), 1-12.

Cohen, S. \& Hochberg, Y.V. (2014). Accelerating startups: The seed accelerator phenomenon. Retrieved July 22, 2019, from https://ssrn.com/abstract=2418000.

Cohen, S., Bingham, C.B. \& Hallen, B.L. (2019b). The role of accelerator designs in mitigating bounded rationality in New Ventures. Administrative Science Quarterly, 64(4), 810-854.

Cohen, S., Fehder, D., Hochberg, Y., \& Murray, F. (2019a). The design of startup accelertors. Research Policy, 48(7), $1781-1797$.

Cohen, S.L., (2013). What do accelerators do? Insights from incubators and angels. Innovations: Technology, Governance, Globalization, 8(3-4), 19-25.

Crișan, E.L., Salanță, I.I., Beleiu, I.N., Bordean O.N. \& Raluca B., (2021). A systematic literature review on accelerators, The Journal of Technology Transfer, 46, 62-89.

D’Alvano, L. \& Hidalgo, A. (2012). Innovation management techniques and development degree of innovation process in service organizations. RङD Management, 42(1), 60-70.

Dimitriadis, E., Anastasiades, T. Karagiannidou, D. \& Lagaki, M. (2018). Creativity and entrepreneurship: The role of gender and personality. International Journal of Business and Economic Sciences Applied Research, 11(1), 7-12.

Dams, M.C., Sarria-Allende, V., Pasquini R. \& Robiolo, G. (2017). Accelerators, Networks and Venture Capital Financing, Academy of Management Proceedings, 2016. 
Dick, B. (1997). Action Learning and Action Research. Retrieved September 22, 2020, from www.scu.edu.au/schools/gcm/ar/arp/actlearn.html.

Drori, I., \& Wright, M. (2018). Accelerators: characteristics, trends and the new entrepreneurial ecosystem. In M. Wright (Ed.), Accelerators: Successful venture creation and growth, 1-20, Edward Elgar Publishing, Cheltenham.

GEM, 2020, GREECE 2018-2019 report. IOBE, Retrieved May 13, 2020, from http://iobe.gr/docs/research/RES_02_11122019_REP_GR.pdf

Guertler, M., Kriz, A. \& Sick, N., (2020). Encouraging and enabling action research in innovation management. RङDD Management, $50(3) 380-395$.

Goldfarb, B., Kirsch D. \& Miller, D. (2007), Was there too little entry during the Dot Com Era?, Journal of Financial Economics, $86(1), 100-144$.

Hallen, B., Cohen, S., Bingham, C. (2019). Do Accelerators Work? If so, How? Organization Science, 3 1(2), $378-414$.

Hathaway, I. (2016). What startup accelerators really do? Harvard Business Review. Retrieved September 3, 2020, from https://hbr.org/2016/03/what-startup-accelerators-really-do.

Hidalgo, A., \& Albors, J. (2008). Innovation management techniques and tools. A review from theory and practice. RE̊D Management, 38(2) 113-127.

Katimertzopoulos, F. \& Vlados, C. (2015). Local Support Mechanisms for Entrepreneurship: The Approach of Local Development and Innovation Institutions. International Journal of Business and Economic Sciences Applied Research, 10(1), 30-41.

Karafolas S. and Woźniak, M. (2020). The Development of Small Enterprises During and After Crisis: Comparative Analysis of Greece and Poland. International Journal of Business and Economic Sciences Applied Research, 13(2).

Karadzic, V., Drobnjak, R. \& Manijeh, R. (2015). Opportunities and Challenges in Promoting Youth Entrepreneurship in Montenegro. International Journal of Business and Economic Sciences Applied Research, 8(3), 13-20.

Kilcrease, K. (2012) The Batavia industrial centre: The hatching of the world's first incubator. New York History, 93(1), 71-93.

Levin, M. (2012). Academic integrity in action research. Action Research, 10(2), 133-149.

Livieratos, A. (2009). Developing a research design supportive framework for constructivist management studies: A meta-analysis of a research project. Paper presented at the 8th European Conference on Research Methods in Business and Management, 19-22 June, Malta.

Livieratos, A. \& Siemos, V (2020). Standardize or customize business acceleration programs? The multistage model of Archimedes accelerator, ISPIM Connects Global Conference Proceedings, 6-8 December, Online event, 1-12

Livieratos, A. \& Lepeniotis, P (2017). Corporate venture capital programs of European electric utilities: Motives, trends, strategies and challenges, The Electricity Journal 3 (2), 30-40

Livieratos, A. \& Dimitrakopoulos, Y. (2020). Accelerating technology transfer. The" Develop Protect Commercialize" model, ISPIM Connects Global Conference Proceedings, 6-8 December, Online event, 1-16

Maurya, A. (2012) Running lean, O'Reilly Media, New York.

Metcalf, L. E., Katona, T. M., and York, J. L. (2020). University startup accelerators: startup launchpads or vehicles for entrepreneurial learning? Entrepreneurship Education and Pedagogy.

Miller, P. \& Bound, K. (2011) The start-up factories: the rise of accelerator programmes to support new technology ventures, NESTA, London

Pauwels, C., Clarysse, B., Wright, M., \& Van Hove, J. (2016). Understanding a new generation incubation model: the accelerator. Technovation, 50, 13-24

Reich, R. (1991). The work of nations, Simon \& Schuster, London, UK.

Ries, E. (2011). The lean startup. Crown Publishing, New York.

Roberts, P. \& Kemper, R. (2017). Startup Accelerators Have Become More Popular in Emerging Markets - and They're Working. Retrieved September 3, 2020, from https://hbr.org/2017/10/startup-accelerators-have-become-morepopular-in-emerging-marketsand-theyre-working

Sheng, C., Chan, C.S.R., Patel, P.C., \& Phan, P.H. (2020). Do differences among accelerators explain differences in the performance of member ventures? Evidence from 117 accelerators in 22 countries. Strategic Entrepreneurship Journal, 14, 224 -239.

Smith, S.W., Hannigan, T.J., \& Gasiorowski, L. (2016). Peering inside: how do peer effects impact entrepreneurial outcomes in accelerators? Academy of Management Proceedings.

Startup Genome (2021). The Global Startup Ecosystem Report. London, UK.

Swann, C. (2002). Action research and the practice of design. Design Issues, 18(1) 49-61.

Tether, B.S. \& Storey, D.J. (1998) Smaller firm's and Europe's high-technology sectors: A framework for analysis and some statistical evidence. Research Policy, 26, 947-971.

Thompson D. (2013). Accelerating the growth of the next generation of innovators. Ohio State Entrepreneurial Business Law Journal, 8(2), 379-391.

Winston S., Sheryl, H., Gasiorowski, T.J. \& Laura L., 2013. Accelerators and Crowd-Funding: Complementarity, Competition, orConvergence in the Earliest Stages of Financing New Ventures?, University of Colorado-Kauffman Foundation CrowdFunding Conference, Boulder, USA, July 12-13.

Wise, S., \& Valliere, D. (2014). The impact on management experience on the performance of start-ups within accelerators. The Journal of Private Equity, 18(1), 9-19.

Wright M., Siegel D. S., Mustar P. (2017). An emerging ecosystem for student start-ups. Journal of Technology Transfer, 42(4), 909922

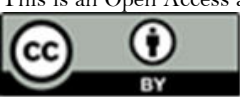

